\title{
Modified thoracoscopic pleural cryo-biopsy in diagnosis of exudative pleural effusion of undetermined etiology
}

\author{
Ayman Ibrahim Baess ${ }^{1 *}$ (D, Essam Gouda Hassanein ${ }^{1}$, Mohamed Al Saeed Emara ${ }^{2}$ and Heba Ahmed Eshmawey ${ }^{1}$
}

\begin{abstract}
Background: Rigid thoracoscopy is the gold standard tool for diagnosing exudative pleural effusion, but sometimes it is difficult to obtain sufficient biopsies using the conventional forceps. This study evaluated the efficacy, safety, and diagnostic value of a modified technique using cryoprobe to obtain pleural biopsies during thoracoscopy.

Results: This is a single-center prospective study in patients that underwent rigid thoracoscopy using conventional rigid forceps followed by a cryoprobe at the same setting after injection of subpleural mixture of adrenaline and xylocaine. Biopsies were reviewed by an independent pathologist; any complications were recorded, and all patients were followed-up post-procedure. Twenty-four patients (12 males; mean age was $56 \pm 15.1$ years) were included. The diagnostic yield of both rigid forceps biopsy (RFB) and cryoprobe biopsy (CPB) was 100\%. CPB had more surface area than RFB with no difference regarding largest diameter $(p=0.064)$. RFB and CPB had similar results regarding presence of fat cells. CPB had much less crushed cells than RFB with better tissue preservation $(p=0.004)$. No significant complications were reported.
\end{abstract}

Conclusions: The modified cryoprobe biopsy is a highly effective and safe way for obtaining pleural biopsy besides affording good quality and size of the biopsy especially in thick firmly adherent pleura.

Keywords: Thoracoscopy, Cryoprobe, Biopsy, Pleural effusion, Modified technique

\section{Background}

Pleural diseases involve the parietal and visceral pleura and may be of either inflammatory or malignant origin, often resulting in pleural effusions. However, $40 \%$ of pleural effusions remain undiagnosed after an initial thoracocentesis [1]. An undiagnosed exudative pleural effusion is often a difficult diagnostic dilemma that needs further histological study for a definitive etiological diagnosis. Pleural biopsy is recommended for evaluation and determination of various etiologies either infectious or malignant ones [2].

Cryo-biopsies of the pleura and lung have been used with success during rigid thoracoscopy with two entry

\footnotetext{
*Correspondence: ayman.baeis@yahoo.com; ayman.baeis@alexmed.edu.eg

${ }^{1}$ Chest Diseases Department, Faculty of Medicine, Alexandria University,

Alexandria, Egypt

Full list of author information is available at the end of the article
}

ports. Authors have also described an analgesic effect of the cold, which made biopsies painless. The tissue was well preserved, and the risk of hemorrhage seemed to be reduced [3]. The aim of this study was to evaluate thoracoscopic pleural cryo-biopsy using the modified technique in diagnosing exudative pleural effusion regarding size, efficacy, and complications.

\section{Methods}

The present study prospectively enrolled 24 patients with undiagnosed exudative pleural effusion who were admitted to the Chest Department of Alexandria Main University Hospital starting from November 2020 to January 2021. Informed consent was taken before starting the study and before performing thoracoscopy according to the guidelines of the ethics committee of Alexandria Faculty of Medicine. The study is approved

\section{Springer Open}

(c) The Author(s). 2021 Open Access This article is licensed under a Creative Commons Attribution 4.0 International License, which permits use, sharing, adaptation, distribution and reproduction in any medium or format, as long as you give appropriate credit to the original author(s) and the source, provide a link to the Creative Commons licence, and indicate if changes were made. The images or other third party material in this article are included in the article's Creative Commons licence, unless indicated otherwise in a credit line to the material. If material is not included in the article's Creative Commons licence and your intended use is not permitted by statutory regulation or exceeds the permitted use, you will need to obtain permission directly from the copyright holder. To view a copy of this licence, visit http://creativecommons.org/licenses/by/4.0/. 
by the ethics committee of the Faculty of Medicine, Alexandria University (ID 0105678) and registered at ClinicalTrials.gov (NCT04683419).

\section{Inclusion criteria}

Patients with exudative pleural effusion for which specific diagnosis could not be determined by routine diagnostic methods

\section{Exclusion criteria}

Patients with severe chronic obstructive pulmonary disease and consequent respiratory insufficiency, significant contralateral lung involvement, trapped lung, unstable cardiovascular status, severe Interstitial lung disease, bleeding diathesis or refusal to undergo medical thoracoscopy. Moreover, there were no perspicuous exclusion criteria based on performance status or medical condition, but patients had to be judged by the operator as capable of undergoing medical thoracoscopy.

All patients underwent thoracoscopy whom biopsies were taken using the modified cryo-biopsy technique and the conventional forceps biopsy technique.

All included patients were subjected to the followings: full history taking including age, gender, smoking index, history of other diseases, and the presenting symptoms; clinical examination including general examination and local chest examination; routine laboratory investigations including complete blood picture, renal function tests, liver function tests, prothrombin activity and international normalized ratio (INR); and radiological evaluation including plain chest $\mathrm{x}$-ray poster-anterior view, computed topography scan of the chest, and ultrasound examination of the pleural cavity. If there was pleural effusion, thoracentesis and pleural fluid analysis were done physically, microscopically (total and differential nucleated cell count), microbiologically, and biochemically including protein-glucose-LDH and cytopathologically. Follow-up chest $x$-ray was done for all patients in the same day of procedure.

\section{Thoracoscopy}

Medical thoracoscopy in the current study was performed mainly in the endoscopy suite of the Chest Department, Alexandria Main University Hospital.

Medical thoracoscopy was performed under sterile conditions. Methods of cleaning, disinfecting, and sterilizing instruments were based on the local hospital infection control unit recommendations. Pulse, blood pressure, respiratory rate, ECG, and oxygen saturation using continuous pulse oximetry were monitored during the whole procedure. Rigid thoracoscope (Karl Storz $\mathrm{GmbH} \&$ Co., Germany) was the scope used in the current study. Instruments for rigid thoracoscopy included the following:
- A metallic trocar with multifunctional valve with insufflation stopcock, $11 \mathrm{~mm}$ in diameter and autoclavable.

- A 10-mm straight forward telescope $0^{\circ}$ with angled eyepiece with a 6-mm working channel (26038AA, K. Storz-Endoskope, Tuttlingen, Germany)

- A 5-mm rotational biopsy forceps with connector pin for uni-polar coagulation (Karl Storz, GmbH \&. Co., Tuttlingen, Germany) was used for taking biopsies from the parietal pleura.

\section{Cryo-equipment}

The cryo-equipment is simple to set up and consists of a cylinder containing a freezing gas (cryogen) stored under high pressure, a console (cryo-machine) that controls the flow of cryogen, and a catheter with a cryoprobe at one end to freeze target tissue by direct contact. The thoracoscopist used a foot pedal to activate and regulate the flow of the cryogen through the catheter from the cylinder to the cryoprobe. The cryo-machine used was Erbokryo CA (Tübingen, Germany).

A flexible cryoprobe with a diameter of $2.4 \mathrm{~mm}$ was used to collect the pleura by firmly attaching it to the biopsy site for a certain amount of time (10-30 s) until ice ball forms then withdrawing the cryoprobe with the attached tissue biopsy (ERBE, Technik GmBH, Tübingen, Germany). A rigid cryoprobe with a diameter of $2.4 \mathrm{~mm}$ was used and the same steps were adopted as in case of using flexible Cryoprobe (2.4 mm, Erbokryo CA, Erbe, Tübingen, Germany). A trans-bronchial needle with $1.8 \mathrm{~mm}$ diameter was used to inject subpleural mixture of lidocaine $2 \%$ and epinephrine diluted by normal saline $9 \%$ to facilitate pleural biopsy using cryotechnique (Aspiration needle ENDO-FLEX, Voerde, Germany).

\section{Phases of medical thoracoscopy performed [4]}

Medical thoracoscopy in the current study was done under local anesthesia (mainly $2 \%$ lidocaine) with moderate sedation (incremental doses of intravenous midazolam 5-10 mg) which was quite well tolerated by patients. In few cases, general anesthesia was applied via anesthesiologist through laryngeal mask when patients refused local anesthesia and moderate sedation.

In the current study, medical thoracoscopy was done using rigid scopes through single-port technique.

\section{Biopsy techniques}

Rigid thoracoscopic forceps pleural biopsies (RFB) were usually taken from the suspected parietal pleural lesions using the rigid forceps. They were always taken against a rib to minimize the risk of vessel or nerve injury. Those biopsies were taken using single-port single-instrument rigid technique through the scope working channel. 
In the same sitting, the cryoprobe biopsy technique (CPB) was then applied after subpleural injection of the diluted mixture of epinephrine and lidocaine $2 \%$ using trans-bronchial needle till subpleural raising and bleb was formed, then introduction of the cryoprobe (either the flexible or the rigid ) to be firmly attached to the biopsy site then the operator uses the cryo-machine pedal for delivering the freezing effect through the cryoprobe for at least 10-30 s until ice ball forms then grasping the cryoprobe with the attached pleural biopsy was done. The tissue attached to the tip of the cryoprobe was spontaneously thawed in normal saline at room temperature; three to five biopsies of suspicious pleural lesions were taken, as shown in Fig. 1.

Important to mention, rigid cryoprobe was applied for the first presenting 10 patients then due to malfunctioning of the rigid probe (and the probe is no longer manufactured by ERBE company); we used a flexible cryoprobe with the same $2.4 \mathrm{~mm}$ diameter attached by adhesive tape to a rigid forceps in the successive 14 patients (Fig. 1c). No biopsies were taken in both techniques (rigid forceps and cryoprobe) from the anterior costoparietal pleura for fear of bleeding secondary to injury of the internal mammary artery or one of its branches.

Pleurodesis was done in the same setting in some cases, if there was high suspicion of malignancy (based on pre-procedure CT chest findings or the intraprocedural presence of pleural masses or sizable pleural nodules). Pleurodesis was done using a powder insufflator which was carried out using $500 \mathrm{mg}$ of oral doxycycline capsules (5 capsules of vibramycin, Pfizer Inc., Germany), with uniform distribution of all particles all over the costal pleural surface [5].

At the end of the procedure, a chest tube was inserted to drain residual air and fluid from the pleural cavity. Chest tube was connected (or primarily inserted after connection) to a thoracic drainage device. The drainage system used in the current study was single-bottle system (the underwater-seal principle).

A chest radiograph was done in the same day. When the lung was seen fully expanded and the pleural fluid drainage was below $150 \mathrm{ml} /$ day, chest tube was removed, occlusive dressing with gauze was applied, chest $\mathrm{x}$-ray was then performed, and the patient was discharged and scheduled for follow-up. Days till chest tube removal were calculated and recorded. Patients could be discharged in the same day of removing the chest tube.

\section{Follow-up of patients}

Follow-up was carried out by post-procedural chest $\mathrm{x}$ ray till chest tube removal after ensuring full lung expansion and discharge from hospital. Post-procedure complications were recorded with emphasis on local site
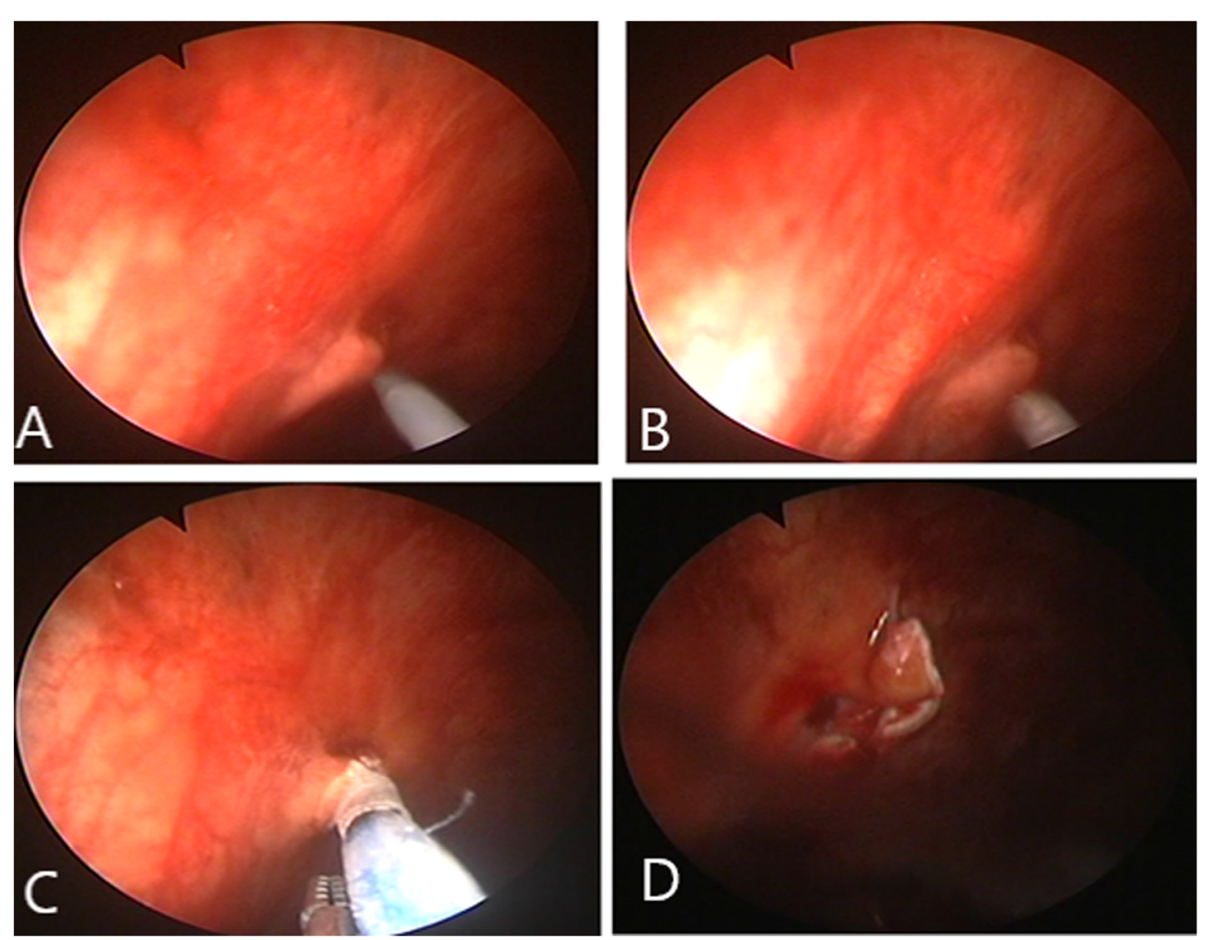

Fig. 1 Steps of the modified thoracoscopic cryo-biopsy technique. a Insertion of the needle. $\mathbf{b}$ Injection of mixed saline and adrenaline subpleurally. c Insertion of the cryoprobe and attaching to the target area of the parietal pleura forming the ice-ball (note that the cryoprobe is attached to a rigid forceps). $\mathbf{d}$ Getting the biopsy 
"wound" infection, pneumothorax/incomplete lung expansion, fever, pain, and bleeding.

\section{Histopathology}

Gross evaluation of the specimens was performed. Paraffin block then was prepared. Tissues were prepared on glass slides and were stained with hematoxylin and eosin (H\&E) stain. The following grading processes were then achieved.

\section{Histopathological grading of fat cell}

Measurement of the quantity of fat cells is an indicator of depth of the taken pleural biopsy [3]. We proposed if there was no presence of fat cells in the obtained pleural biopsies, this was marked as negative "superficial sample", and if fat cells were present in less than $5 \%$ of the biopsy, this was marked as +1 , if $5-25 \%$ of the biopsy was marked as $2+$, and if more than $25 \%$ it was assigned $3+$. This was applied to compare biopsies obtained by both techniques (RFB and CPB) regarding biopsy depth.

\section{Histopathological grading of crushed cells}

Measurement of the quantity of crushed cells in the gained pleural biopsies was an indicator of tissue integrity or viability [3]. If there was no presence of crushed cells in pleural biopsied, this was marked as negative " $\mathrm{A}$ well-integrated, viable biopsy”. If crushed cells were found in less than $5 \%$ of the biopsy, this was marked as $1+$; if $5-25 \%$ of the biopsy, this was marked as $2+$; and if more than $25 \%$, it was graded as $3+$. This was applied to compare the integrity and viability of pleural biopsies obtained by both techniques (RFB and CBP).

\section{Statistical analysis of the data}

Data were fed to the computer and analyzed using IBM SPSS software package version 20.0 (Armonk, NY, IBM Corp.). Wilcoxon signed ranks test, marginal homogeneity test, and McNemar test were used to compare between groups. Significance of the results was judged at the $5 \%$ level.

\section{Results}

Twenty-four patients with undiagnosed pleural effusion were enrolled in this study (12 males (50\%); median age 56 years). Twelve of them had right sided pleural effusion and 2 had bilateral pleural effusion. Demographic data regarding age, gender, and smoking history was illustrated in (Table 1). Dyspnea was the most common symptom (90\%) followed by chest pain (50\%) then cough and loss of weight (Table 1).

Pleural fluid was positive for malignant cells in 2 patients $(8.3 \%)$ (Table 1$)$. In thoracoscopy, the findings were identified and tabulated as shown in Table 1 (Fig. 2). Among the studied patients, 12 patients (50\%) underwent pleurodesis.
The most common complication was pain which was tolerable and did not need any intervention in $79 \%$ of the patients followed by fever then minor bleeding (that needed no further intervention or required interruption of the procedure), unexpanded lung, and wound infection (Table 2). The median number of days till chest tube removal was 3.5 days and for hospital stay was 7 days (Table 2). One patient died after 4 days from the procedure due to advanced malignant mesothelioma.

Specimens taken from the 24 subjects involved in the study were divided as follows.

\section{Group I}

Medical thoracoscopic biopsies by a cryoprobe using the modified technique obtained from the suspicious parietal pleural lesions. This group had been subdivided into two subgroups (Table 2):

- Subgroup (A). Ten patients whom biopsies were taken using rigid cryoprobe.

- Subgroup (B). Fourteen patients whom biopsies were taken using flexible cryoprobe.

\section{Group II}

Medical thoracoscopic biopsies using conventional rigid forceps biopsy obtained from the suspicious parietal pleural lesions from the same 24 patients

\section{Biopsy size}

When comparing the two main groups, there was statistically significant difference regarding biopsy surface area $(p=0.007), \mathrm{CPB}$ were larger $\left(\right.$ mean $\left.=4.1 \pm 2.4 \mathrm{~cm}^{2}\right)$, and RFB (mean $=2.7 \pm 1 \mathrm{~cm}^{2}$ ), but in regard of biopsy largest diameter there was no difference (Table 3, Fig. 3). On the other hand, flexible cryoprobe biopsies surface area was larger (mean $=5 \pm 2.7 \mathrm{~cm}^{2}$ ) compared to rigid cryoprobe biopsy $\left(\right.$ mean $\left.=2.8 \pm 1.4 \mathrm{~cm}^{2}\right)(p=0.043)$, as shown in Table 4, and there was no difference between the two cryoprobes in the aspect of biopsy largest diameter (Table 4).

\section{Diagnostic yield}

Both CPB and RFB reached 100\% diagnostic yield and in both groups; 8 patient (33.3\%) had nonspecific inflammation and 24 patients $(66.7 \%)$ had specific diagnosis either benign or malignant one (Table 3 ).

Also, between the two cryoprobes, there was no difference in the diagnostic yield as in the rigid cryoprobe forceps biopsies there was 10 biopsies, one patient (10\%) with nonspecific inflammation and 9 patients $(90 \%)$ with specific pathology. In flexible cryoprobe forceps biopsies, there were 14 biopsies, 7 patients $(50 \%)$ had nonspecific inflammation and 7 patients (50\%) had specific pathology (Table 4). 
Table 1 Demographic data, clinic-radiologic, and thoracoscopic findings of the studied patients $(n=24)$

\begin{tabular}{|c|c|}
\hline & No. (\%) \\
\hline \multicolumn{2}{|l|}{ Age (years) } \\
\hline$<55$ & $10(41.7 \%)$ \\
\hline$\geq 55$ & $14(58.3 \%)$ \\
\hline Median (min-max) & $56(25-76)$ \\
\hline Mean \pm SD & $53.6 \pm 15.1$ \\
\hline \multicolumn{2}{|l|}{ Gender } \\
\hline Male & $12(50 \%)$ \\
\hline Female & $12(50 \%)$ \\
\hline \multicolumn{2}{|l|}{ Smoking history } \\
\hline Non-smoker & $13(54.2 \%)$ \\
\hline Current or ex-smoker & $11(45.8 \%)$ \\
\hline \multicolumn{2}{|l|}{ Clinical data } \\
\hline Dyspnea & $22(91.7 \%)$ \\
\hline Cough & $9(37.5 \%)$ \\
\hline Chest pain & $12(50 \%)$ \\
\hline Loss of weight & $9(37.5 \%)$ \\
\hline \multicolumn{2}{|l|}{ Chest X-ray (pleural effusion side) } \\
\hline Right side & $12(50 \%)$ \\
\hline Left side & $10(41.7 \%)$ \\
\hline Bilateral & $2(8.3 \%)$ \\
\hline \multicolumn{2}{|l|}{ Pleural fluid malignant cells } \\
\hline Negative & $22(91.7 \%)$ \\
\hline Positive & $2(8.3 \%)$ \\
\hline Metastatic carcinoma & $1(50 \%)$ \\
\hline Poorly differentiated adenocarcinoma & $1(50 \%)$ \\
\hline \multicolumn{2}{|l|}{ Thoracoscopic findings } \\
\hline \multicolumn{2}{|l|}{ Nodules } \\
\hline Absent & $6(25 \%)$ \\
\hline Solitary & $5(20.8 \%)$ \\
\hline Multiple & $10(41.7 \%)$ \\
\hline Diffuse & $3(12.5 \%)$ \\
\hline \multicolumn{2}{|l|}{ Masses } \\
\hline Absent & $14(58.3 \%)$ \\
\hline Solitary & $3(12.5 \%)$ \\
\hline Multiple & $5(20.8 \%)$ \\
\hline Diffuse & 2 (8.3\%) \\
\hline \multicolumn{2}{|l|}{ Plaques } \\
\hline Absent & 18 (75\%) \\
\hline Solitary & $2(8.3 \%)$ \\
\hline Multiple & $4(16.7 \%)$ \\
\hline Diffuse & $0(0 \%)$ \\
\hline \multicolumn{2}{|l|}{ Adhesions } \\
\hline Absent & 17 (70.8\%) \\
\hline
\end{tabular}

Table 1 Demographic data, clinic-radiologic, and thoracoscopic findings of the studied patients $(n=24)$ (Continued)

\begin{tabular}{ll}
\hline & No. (\%) \\
\hline Present & $7(29.2 \%)$ \\
Pleural thickening & \\
Absent & $4(16.7 \%)$ \\
Present & $20(83.3 \%)$ \\
Diffuse & $13(65 \%)$ \\
Focal & $7(35 \%)$ \\
Procedure side & \\
Right side & $13(54.2 \%)$ \\
Left side & $11(45.8 \%)$ \\
\hline
\end{tabular}

\section{Biopsy depth}

In the current study, the biopsy depth was assessed by the presence of fat cells and there was no significant difference between both the CPB and the RFB in the quantity of fat cells (Table 3). When comparing the two cryoprobes regarding the quantity of fat cells also, there was no significant difference (Table 4).

\section{Biopsy Integrity and quality}

The present study depended on the quantity of crushed cells in the assessment of the integrity/quality of the biopsy and regarding that issue, the CBP had significant difference with far less crushed artifacts than the RFB with $p=0.004$ (Table 3, Fig. 4). However, the two cryoprobes biopsies had no significant difference in the same regard (Table 4).

\section{Discussion}

Pleural biopsy is indicated to define the etiology of pleural diseases; the biopsy obtaining techniques are variable starting from the older ones such as blind pleural biopsy reaching the newer techniques such as image-guided pleural biopsy and thoracoscopy-guided pleural biopsy [6].

The use of cryo-technique has been performed for some time to acquire both bronchoscopic biopsies and thoracoscopic pleural biopsies targeting the improvement of biopsy diagnosis, size, and quality. However, pleural cryo-biopsy always had its limitations such as fear of bleeding due to large size of the biopsy and difficulty of acquiring biopsy in firmly adherent or thickened pleural membranes, but as they say "modern problems require modern solutions", so the modified thoracoscopic cryo-biopsy technique was done in the current study to facilitate obtaining biopsy and to acquire a large sized biopsy without the fear of profound bleeding or pain [3].

The injection of subpleural mixture of xylocaine and diluted adrenaline was first described in 2008 in the 


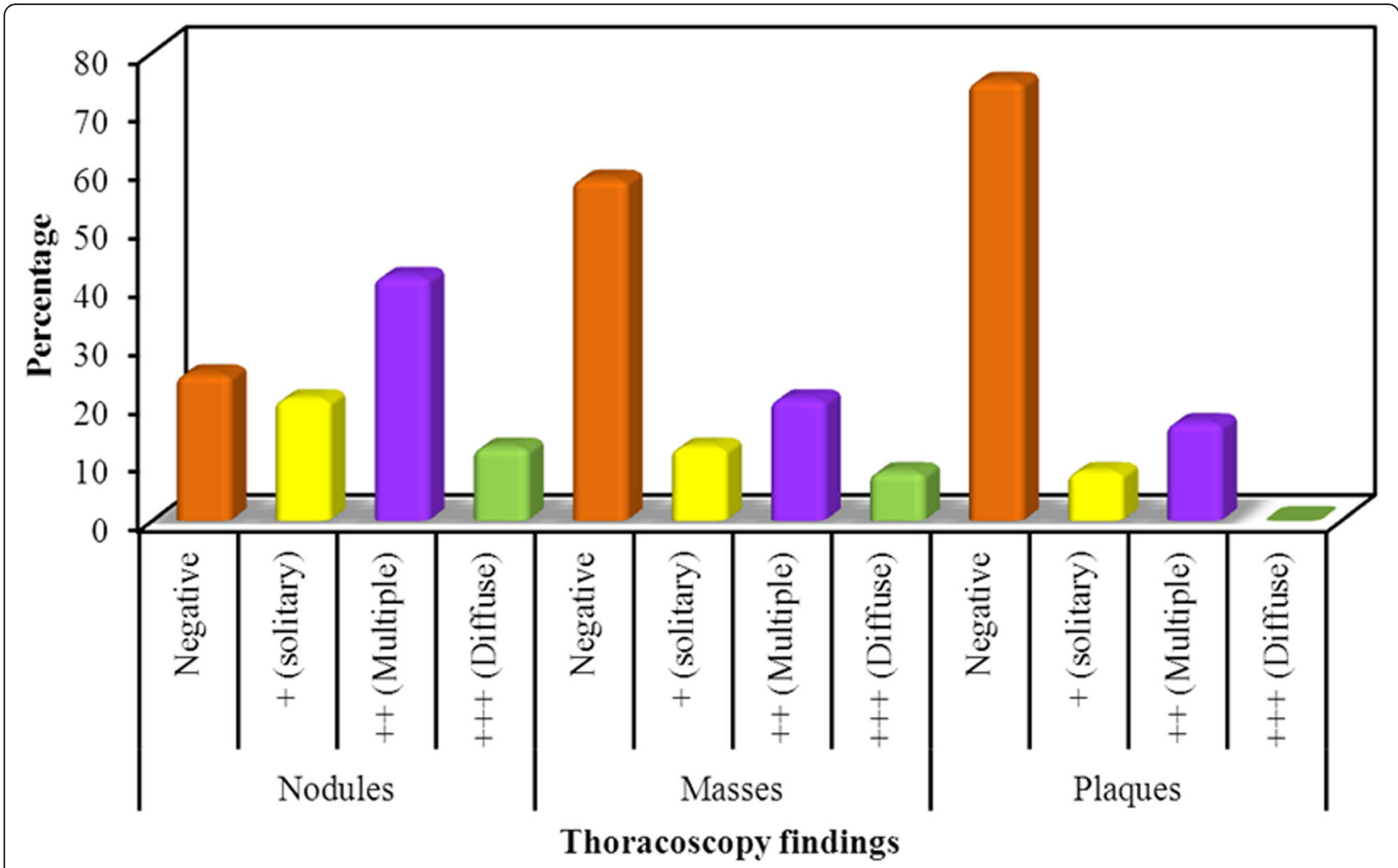

Fig. 2 Distribution of the studied cases according thoracoscopy findings $(n=24)$

study performed by Sasada et al. [6], using an insulated tip diathermic knife after injection of the subpleural mixture for raising the pleura and improving diagnosis with promising results.

In an Egyptian study by Ahmed et al. [7], they reported that pleural cryo-biopsies have a high diagnostic yield similar to rigid forceps biopsy $(76.7 \%)$, and it showed better performance in thin highly vascular

Table 2 Distribution of the studied cases according to complications and duration of hospital stay $(n=24)$

\begin{tabular}{ll}
\hline & No. (\%) \\
\hline Complications & $19(79.2 \%)$ \\
Bleeding & $7(29.2 \%)$ \\
Fever & $8(33.3 \%)$ \\
Wound infection & $2(8.3 \%)$ \\
$\quad$ Unexpanded lung & $4(16.7 \%)$ \\
Days till chest tube removal & $\mathbf{n}=\mathbf{2 4}$ \\
$\quad$ Median (min-max) & $3.5(3-7)$ \\
$\quad$ Mean \pm SD & $3.8 \pm 1.1$ \\
Duration of hospital stay in days & \\
$\quad$ Median (min-max) & $7(4-11)$ \\
Mean \pm SD & $7.1 \pm 1.9$ \\
\hline
\end{tabular}

pleura where obtaining biopsies can be performed with minimal risk of bleeding.

In the current study, the diagnostic yield reached $100 \%$, regarding both rigid forceps biopsies and cryoprobe biopsies. Furthermore, there was no difference while using different types of cryoprobes in the diagnostic accuracy compared with each other.

Similar to our results, Rozman et al. [8] (in a prospective study including 84 patients comparing semirigid thoracoscopy with rigid thoracoscopy) reported that the diagnostic yield was $97.6 \%$ in the semirigid thoracoscopy arm compared with $100 \%$ in the rigid thoracoscopy arm with no significant difference; only the biopsy size in the semirigid thoracoscopy was smaller.

As regards the biopsy size in the current study, there was a statistically significant difference between the cryoprobe and the rigid thoracoscopic forceps, according to the specimen surface area as the cryoprobe biopsy yielded a larger biopsy with a mean surface area of 2.43 $\mathrm{cm}^{2}$ compared with the rigid forceps biopsy with a mean of $1.04 \mathrm{~cm}^{2}$ which might be explained by the longer time for freezing effect (around 10-30 s) compared with other studies $[3,9]$ which allowed more tissue freezing and larger area for biopsy; however, when comparing the two biopsies regarding the largest diameter, there was no significant difference because the forceps punch biopsy 
Table 3 Comparison between cryoprobe and rigid forceps according to different parameters $(n=24)$

\begin{tabular}{|c|c|c|c|}
\hline & Cryoprobe & Rigid forceps & $p$ \\
\hline \multicolumn{4}{|l|}{ Biopsy surface area in $\mathrm{cm}^{2}$} \\
\hline Median (min-max) & $3.6(0.1-9)$ & $3(1.4-6)$ & \multirow[t]{2}{*}{${ }^{z} p=.007^{*}$} \\
\hline Mean \pm SD & $4.1 \pm 2.4$ & $2.7 \pm 1$ & \\
\hline \multicolumn{4}{|l|}{ Biopsy largest diameter in cm } \\
\hline Median (min-max) & $3(0.3-3.5)$ & $2(2-3)$ & \multirow[t]{2}{*}{${ }^{z} p=0.064$} \\
\hline Mean \pm SD & $2.7 \pm 0.8$ & $2.4 \pm 0.5$ & \\
\hline \multicolumn{4}{|l|}{ Specific pathology } \\
\hline Nonspecific inflammation & $8(33.3 \%)$ & $8(33.3 \%)$ & \multirow[t]{2}{*}{$\mathrm{McN}_{p}=1.000$} \\
\hline Malignant & $16(66.7 \%)$ & $16(66.7 \%)$ & \\
\hline \multicolumn{4}{|l|}{ Fat cells } \\
\hline Negative & $12(50 \%)$ & $8(33.3 \%)$ & \multirow[t]{4}{*}{${ }^{\mathrm{MH}} p=0.307$} \\
\hline$+(<5 \%)$ & $4(16.7 \%)$ & $8(33.3 \%)$ & \\
\hline$++(5-10 \%)$ & $5(20.8 \%)$ & $2(8.3 \%)$ & \\
\hline$+++(10-25 \%)$ & $3(12.5 \%)$ & $6(25 \%)$ & \\
\hline \multicolumn{4}{|l|}{ Crushed cells } \\
\hline Negative & $17(70.8 \%)$ & $6(25 \%)$ & \multirow[t]{4}{*}{${ }^{\mathrm{MH}} p=0.004^{*}$} \\
\hline$+(<5 \%)$ & $6(25 \%)$ & $14(58.3 \%)$ & \\
\hline$++(5-10 \%)$ & $1(4.2 \%)$ & $0(0 \%)$ & \\
\hline$+++(10-25 \%)$ & $0(0 \%)$ & $4(16.7 \%)$ & \\
\hline
\end{tabular}

$Z$ Wilcoxon signed ranks test, $M H$ marginal homogeneity test, $M c N$ McNemar test, $p p$ value for comparing between pleural biopsies taken by cryoprobe and rigid forceps

*Statistically significant at $p \leq 0.05$

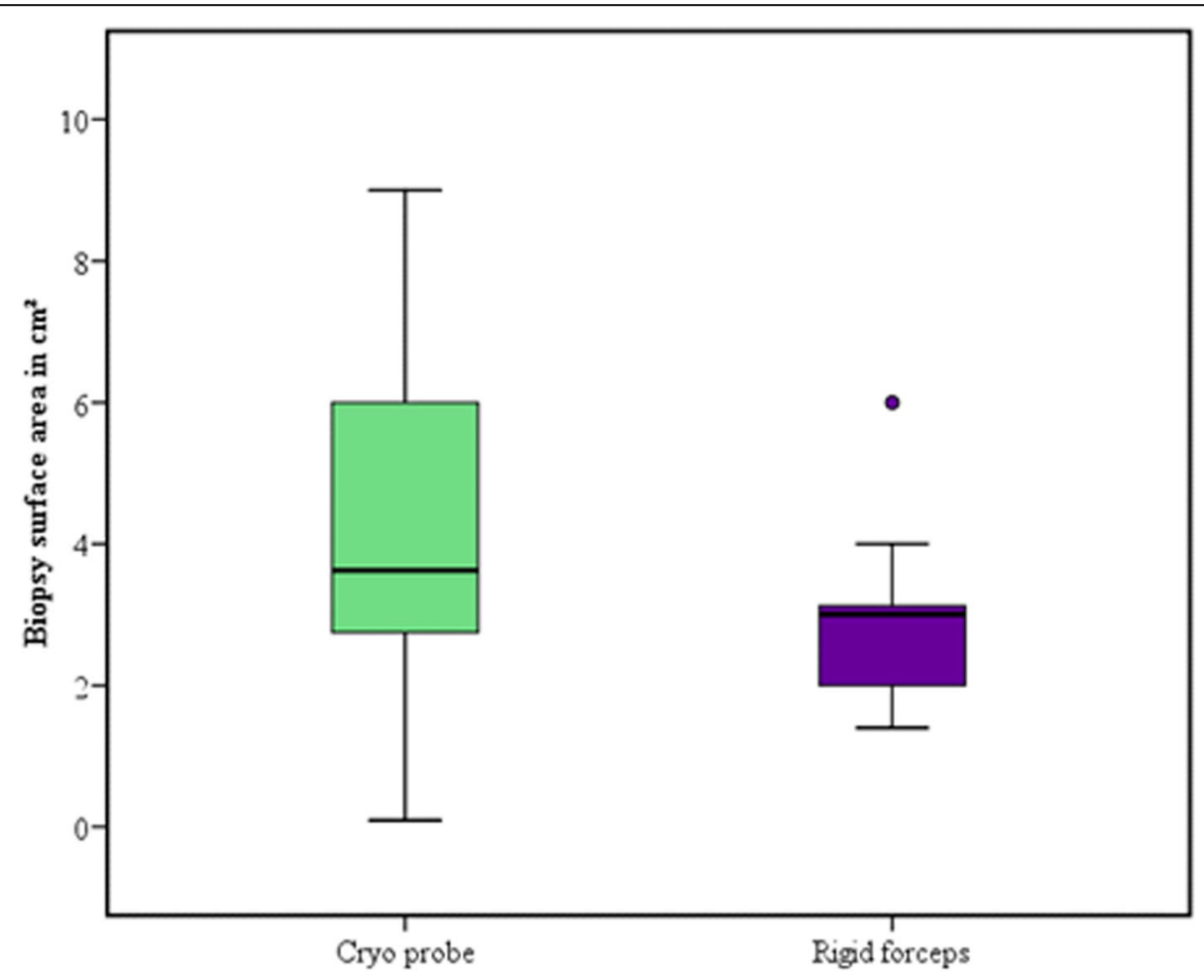

Fig. 3 Comparison between cryoprobe and rigid forceps according to biopsy surface area $(n=24)$ 
Table 4 Relation between type of cryoprobe used and different parameters $(n=24)$

\begin{tabular}{|c|c|c|c|c|}
\hline & \multicolumn{2}{|c|}{ Type of cryoprobe used } & \multirow{2}{*}{$\begin{array}{l}\text { Test of } \\
\text { significance }\end{array}$} & \multirow[t]{2}{*}{$p$} \\
\hline & Rigid $(n=10)$ & Flexible $(n=14)$ & & \\
\hline \multicolumn{5}{|l|}{ Surface area in $\mathrm{cm}^{2}$} \\
\hline Median (min-max) & $3.3(0.1-4.6)$ & $2.7(0.2-9)$ & $U=35.50^{*}$ & $0.043^{*}$ \\
\hline Mean \pm SD & $2.8 \pm 1.4$ & $5 \pm 2.7$ & & \\
\hline \multicolumn{5}{|l|}{ Largest diameter in $\mathrm{cm}$} \\
\hline Median (min-max) & $2.5(0.3-3.5)$ & $3(0.5-3.5)$ & $U=62.50$ & 0.642 \\
\hline Mean \pm SD & $2.6 \pm 1$ & $2.7 \pm 0.8$ & & \\
\hline \multicolumn{5}{|l|}{ Fat cells } \\
\hline Negative & $6(60 \%)$ & $6(60 \%)$ & $x^{2}=1.650$ & ${ }^{M C} C_{p}=0.682$ \\
\hline$+(<5 \%)$ & $2(20 \%)$ & $2(14.3 \%)$ & & \\
\hline ++ (5-10\%) & $1(10 \%)$ & $4(28.6 \%)$ & & \\
\hline$+++(10-25 \%)$ & $1(10 \%)$ & $2(14.3 \%)$ & & \\
\hline \multicolumn{5}{|l|}{ Crushed cells } \\
\hline Negative & $6(60 \%)$ & $11(78.6 \%)$ & $x^{2}=1.846$ & ${ }^{M} C_{p}=0.468$ \\
\hline$+(<5 \%)$ & $3(30 \%)$ & $3(21.4 \%)$ & & \\
\hline$++(5-10 \%)$ & $1(10 \%)$ & $0(0 \%)$ & & \\
\hline \multicolumn{5}{|l|}{ Specific pathology "Cryoprobe" } \\
\hline Nonspecific inflammation & $1(10 \%)$ & $7(50 \%)$ & $x^{2}=4.20$ & $\mathrm{FE}_{p}=0.079$ \\
\hline Malignant & $9(90 \%)$ & $7(50 \%)$ & & \\
\hline
\end{tabular}

$x^{2}$ Chi square test, FE Fisher exact, MC Monte Carlo, $U$ Mann-Whitney test, $p p$ value for association between two categories *Statistically significant at $p \leq 0.05$

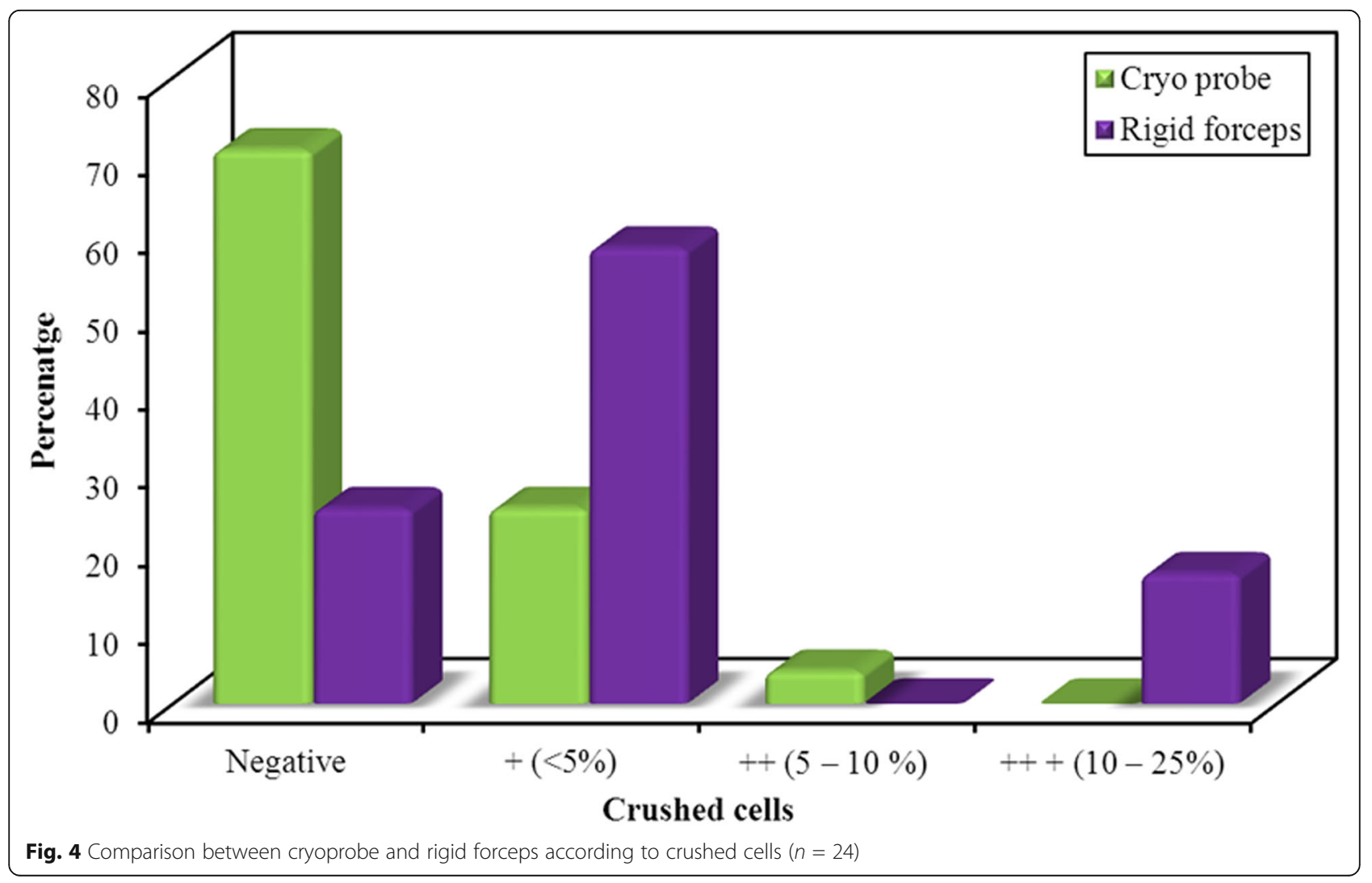


obtained a large biopsy although it might be thinner, and for this reason we used two different ways for assessing biopsy size.

Also, when comparing the two types of cryoprobe used, there was a significant difference between the rigid cryoprobe and the flexible one; the last obtained a larger biopsy regarding specimen surface area with a mean of $2.65 \mathrm{~cm}^{2}$ compared with $1.36 \mathrm{~cm}^{2}$ in the rigid cryoprobe. The explanation of this contradiction is that the rigid cryoprobe was the older probe with lesser quality than the new flexible probe and we used rigid forceps and attached it to the flexible cryoprobe when obtaining the biopsy to ease the targeting of the biopsy site.

As described by Ganganah et al. [10], in a retrospective systemic review and meta-analysis which included 8 studies comparing cryo-biopsy versus conventional bronchoscopic biopsy in 916 patients, specimen area $\left(\mathrm{mm}^{2}\right)$ was significantly larger in the cryo-biopsy than forceps biopsies (standard mean difference $=1.21,95 \%$ confidence interval $(0.94,1.48), p<0.00001)$. The diagnostic rate was significantly higher in the cryo-biopsy than forceps biopsies (risk ratio 1.36, 95\% confidence interval $(1.16,1.59), p=0.0002)$ while there was no significant difference regarding risk of bleeding.

In context with the current study, a study was conducted by Tousheed et al. [11], prospectively comparing semirigid thoracoscopic cryo-biopsy versus conventional forceps biopsy in 87 patients, it was reported that the mean specimen size for cryo-biopsy was $13.2 \pm 6.7 \mathrm{~mm}$ which was significantly larger compared with the conventional forceps biopsy with an average of $6.8 \pm 3.3$ $\mathrm{mm}$ and the diagnostic accuracy of the cryoprobe was $99 \%$ and for the forceps biopsy it was $96 \%$. However, the author reported some warnings regarding the semirigid thoracoscopy such as keeping thoracoscopy in neutral position while grasping the probe otherwise both the probe and thoracoscopy might be damaged, something which had no place while using rigid thoracoscopy.

Recently, Pathak et al. [12], in a prospective study included 10 patients who underwent semirigid thoracoscopic forceps biopsy followed by cryoprobe biopsy; they stated that the mean cumulative tissue volume with forceps biopsy was $80 \mathrm{~cm}^{3}$ and the mean cumulative tissue volume with cryo-biopsy was $320 \mathrm{~cm}^{3}, p=0.007$ which meant bigger biopsy size with the cryoprobe. The diagnostic yield was similar in the two groups and the author did not mention percentage regarding this aspect.

In the present study, it has been found that when comparing the cryoprobe biopsy with the rigid forceps' biopsy regarding the presence of fat cells, there was no difference between both groups regarding the quantity of fat cells and hence the depth of the biopsies taken. Nevertheless, there was a significant difference between both groups regarding the biopsy size (in favor of the cryo-biopsy). Also, when comparing the two types of the cryoprobe, there was no difference in the quantity of fat cells neither in the rigid nor the flexible cryoprobe.

However, in 2015, Maturu et al. [13], conducted a prospective study (which included 6 patients), and it revealed different observations; the depth of the biopsy was more in the cryoprobe hand than the forceps biopsies assessed by the presence of adipose tissues. However, the author did not mention the grading of the presence of adipose tissue. These results can be explained by the small sample size; furthermore, the biopsies of only 4 patients were taken by conventional forceps, so the results might be deceiving.

Contradictory results were reported by Thomas et al. [9], their retrospective study was conducted on 22 patients and included the use of conventional forceps biopsy followed by cryoprobe biopsy through semirigid thoracoscopy in the same setting. They stated that deeper tissue was acquired using the cryoprobe particularly in mesothelioma, but the author did not mention the assessment of the quantity of adipose tissue; only the presence was mentioned .

The difference between the results of the present study and those of Thomas et al. [9] may be due to the freezing material used; in the study published in 2015, the author mentioned that the cryoprobe tip cooled to -89.5 ${ }^{\circ} \mathrm{C}$ within seconds after activation which means they used liquid nitrogen and it is a more powerful freezing agent than the liquid carbon dioxide used in the current study and it is known that the freezing temperature of liquid carbon dioxide never exceeds $-78{ }^{\circ} \mathrm{C}$. Thus, cryotechnique using liquid nitrogen allows better freezing area and more deeper tissue penetration.

Another item regarding the quality of the biopsy is the crushed cells or the presence of artifacts and in the current study there was a significant difference between the cryoprobe and the rigid forceps biopsies as the cryoprobe had far less crushed cells in its biopsies measured by the same grading used to assess the quantity of fat cells.

However, when comparing the two types of the cryoprobe used, there was no significant difference which means that the difference was related to the technique not the cryoprobe used.

These findings are consistent with the results reported by Rozman et al. [3], in the prospective study conducted on 15 patients which used the same grading mechanism of the quantity of crushed cells and quality of the pleural biopsy and found that the cryoprobe biopsy was superior to the conventional forceps biopsy in the quality with less number of crushed cells although obtaining the biopsy was done through a pleuroscope.

In the study mentioned before, Rozman et al. [3] agreed with the current study findings regarding the quality of the biopsy and stated that the majority of the 
cryoprobe samples were assessed as "easily interpretable" or "interpretable with some difficulty" which reflected minimal amount of the artifacts observed by the pathologists.

Regarding complications in the present study, it has been found that all the patients tolerated the procedure; there were 17 patients who complained of post-operative local pain that required no modification in the analgesics regimen and 7 patients who had local bleeding at the site of the biopsy that required no intervention or interruption of the procedure, and there were 2 patients who suffered from local intercostal tube wound infection that required modification of their treatment and eventually were resolved. Four of the 24 patients had unexpanded lung in the follow-up chest $\mathrm{x}$-ray that required further hospital stay, and 8 patients had self-limiting fever that continued for less than 3 days. One patient died after 4 days from the procedure due to advanced malignant mesothelioma.

Similarly, Rozman et al. [3], reported that there was no significant bleeding in the studied 42 biopsies acquired from the 15 patients but also stated that there was no confirmation that the cryo-biopsy was a painless technique.

The study performed by Wanget al [14]., found that during the 9-year study, among the minor adverse events that occurred, 367 (44.1\%) patients had local pain requiring additional analgesic and $5.3 \%$ of the patients had transient self-limited fever $\left(38{ }^{\circ} \mathrm{C}\right.$ or more). No major bleeding was found, and minor bleeding was seen in $4.6 \%$ of the patients. These findings are consistent with the results of the present study.

There were some limitations to the current study. The sample size in this study was relatively small so a large, prospective study is required to validate the observations reported. The present study was conducted in one center in Alexandria Faculty of Medicine; further multicenter study should be initiated for better knowledge and results accuracy.

The only reason for using two different cryoprobes was the poor quality of the rigid cryoprobe and failure of the probe of conducting the freezing effect to its tip after managing 10 cases. ERBE company is no longer manufacturing that type of rigid probes. However, we managed to use this as two subgroups comparison.

Another limitation when using the flexible cryoprobe was the difficulty of targeting the biopsy site through the rigid thoracoscope which required attaching the flexible probe to a thin rigid forceps via adhesive tape as a stent to facilitate targeting the costal pleura.

Other limitations for routine use of pleural cryobiopsy include availability of the equipment, additional cost of the apparatus, cost and place for recharging the cryogen, and the need for highly experienced operators.
Regarding the points of strength of the present study, this was a prospective study that involved two techniques in the same patient in the same setting and same biopsy site which allowed reduction of selection bias and reasonable results.

The use of rigid thoracoscope instead of the semirigid one permitted obtaining longer freezing time using the cryoprobe without the fear of damaging the thoracoscope by the icing effect.

To the best of our knowledge, this is the first study to compare the cryoprobe biopsy with the conventional forceps biopsy using the modified technique of raising the pleura which allowed larger biopsies with longer freezing time without fear of bleeding, pain, or inadequate biopsy.

\section{Conclusion}

Thoracoscopic pleural cryo-biopsy using the modified technique in diagnosing exudative pleural effusion is a feasible and safe procedure.

It is highly effective in thick firmly adherent pleura in obtaining larger biopsies which are difficult to obtain using conventional forceps.

The biopsies obtained by the cryo-technique cellular architecture and tissue integrity were better preserved compared with conventional forceps; this allowed preparation of high-quality histopathological biopsies with good integrity.

\section{Abbreviations \\ RFB: Rigid forceps biopsy; CPB: Cryoprobe biopsy; LDH: Lactate dehydrogenase; INR: International normalized ratio}

\section{Acknowledgements}

All authors are highly acknowledging Prof. Suzan Helal, Professor of Pathology, Alexandria University, for her kind help and prompt support in preparing and examining all pleural biopsies obtained.

\section{Authors' contributions}

AB has conceived the idea and performed thoracoscopy to the studied cases. $M E$ collected data and assisted in performing the procedure. $A B, E G, H E$, and ME have substantially contributed to interpretation and analysis of data. $A B, H E$, and ME have substantially contributed to writing the manuscript. The authors revised and approved the final manuscript.

\section{Funding}

Nil. This research did not receive any specific grant from funding agencies in the public, commercial, or not-for-profit sectors.

\section{Availability of data and materials}

The data sets used and/or analyzed during the current study are available from the corresponding author on reasonable request.

\section{Declarations}

\section{Ethics approval and consent to participate}

Informed written consent was taken from all participants before enrolment in the study. The ethics committee of the Faculty of Medicine, Alexandria University, approved this research (protocol ID 0105678).

The current study is registered at ClinicalTrials.gov. Registration number is NCT04683419. Record verification was at December 2020. Date of enrolment of the first patient was November 11, 2020. Study completion was at January 31, 2021. 


\section{Consent for publication}

Not applicable

\section{Competing interests}

The authors declare that they have no competing interests.

\section{Author details}

'Chest Diseases Department, Faculty of Medicine, Alexandria University, Alexandria, Egypt. ${ }^{2}$ Damanhour Hospital of Chest Diseases, Damanhur, Egypt.

Received: 19 February 2021 Accepted: 5 April 2021

Published online: 15 April 2021

\section{References}

1. Porcel JM, Light RW (2006) Diagnostic approach to pleural effusion in adults. Am Fam Physician. 73(7):1211-1220

2. Beheshtirouy S, Kakaei F, Mirzaaghazadeh M (2013) Video assisted rigid thoracoscopy in the diagnosis of unexplained exudative pleural effusion. J Cardiovasc Thorac Res. 5(3):87-90

3. Rozman A, Camlek L, Marc Malovrh M, Kern I, Schonfeld N (2016) Feasibility and safety of parietal pleural cryobiopsy during semi-rigid thoracoscopy. Clin Respir J. 10(5):574-578. https://doi.org/10.1111/crj.12256

4. Loddenkemper R, Lee $P$, Noppen M, Mathur P (2011) Medical thoracoscopy/ pleuroscopy: step by step. Breathe. 8(2):156-167. https://doi.org/10.1183/2 0734735.011611

5. Hatata EA, Daabis RG, El Sabaa BM, Baess Al, Abd El-Rahman IA (2017) Doxycycline poudrage: an old agent for a new technique. Eg J Chest Dis Tuberc 66(2):331-338. https://doi.org/10.1016/j.ejcdt.2016.08.012

6. Sasada S, Kawahara K, Kusunoki Y, Okamoto N, Iwasaki T, Suzuki H, Kobayashi M, Hirashima T, Matsui K, Ohta M, Miyazawa T (2009) A new electrocautery pleural biopsy technique using an insulated-tip diathermic knife during semirigid pleuroscopy. Surg Endosc. 23(8):1901-1907. https:// doi.org/10.1007/s00464-008-0263-8

7. Ahmed M, AlSharkawy S, Shoukri A, AbouBakr Y (2019) Evaluation of safety and diagnostic yield of pleural cryobiopsies during thoracoscopy. Egypt J Bronchol. 13(1):63-66. https://doi.org/10.4103/ejb.ejb_48_18

8. Rozman A, Camlek L, Marc-Malovrh M, Triller N, Kern I (2013) Rigid versus semi-rigid thoracoscopy for the diagnosis of pleural disease: a randomized pilot study. Respirology. 18(4):704-710. https://doi.org/10.1111/resp.12066

9. Thomas R, Karunarathne S, Jennings B, Morey S, Chai SM, Lee YC et al (2015) Pleuroscopic cryoprobe biopsies of the pleura: a feasibility and safety study. Respirology. 20(2):327-332. https://doi.org/10.1111/resp.12441

10. Ganganah O, Guo SL, Chiniah M, Li YS (2016) Efficacy and safety of cryobiopsy versus forceps biopsy for interstitial lung diseases and lung tumours: a systematic review and meta-analysis. Respirology. 21(5):834-841. https://doi.org/10.1111/resp.12770

11. Tousheed SZ, Manjunath PH, Chandrasekar S, Murali Mohan BV, Kumar H, Hibare KR, Ramanjaneya R (2018) Cryobiopsy of the pleura: an improved diagnostic tool. J Bronchology Interv Pulmonol. 25(1):37-41. https://doi. org/10.1097/LBR.0000000000000444

12. Pathak V, Shepherd RW, Hussein E, Malhotra R (2017) Safety and feasibility of pleural cryobiopsy compared to forceps biopsy during semi-rigid pleuroscopy. Lung. 195(3):371-375. https://doi.org/10.1007/s00408-0179998-0

13. Maturu VN, Sehgal IS, Dhooria S, Bal A, Aggarwal AN, Behera D, Agarwal R (2015) Pleuroscopic cryobiopsy: case series and systematic review. J Bronchology Interv Pulmonol. 22(3):e11-e13. https://doi.org/10.1097/LBR 0000000000000193

14. Wang XJ, Yang Y, Wang Z, Xu LL, Wu YB, Zhang J, Tong ZH, Shi HZ (2015) Efficacy and safety of diagnostic thoracoscopy in undiagnosed pleural effusions. Respiration. 90(3):251-255. https://doi.org/10.1159/000435962

\section{Publisher's Note}

Springer Nature remains neutral with regard to jurisdictional claims in published maps and institutional affiliations.

\section{Submit your manuscript to a SpringerOpen ${ }^{\circ}$ journal and benefit from:}

- Convenient online submission

- Rigorous peer review

- Open access: articles freely available online

- High visibility within the field

- Retaining the copyright to your article

Submit your next manuscript at $\boldsymbol{\nabla}$ springeropen.com 